kind. A little forethought on the part of the mistress, both as to the arrangements for bathing and time to bathe in, would surely find a way out of the difficulty, and, of course, the force of example goes for a great deal; when the servants find that their mistress makes a special point of the daily bath (which, alas, is not always the case) in nine cases out of ten they will overcome many difficultics to follow her example.

\title{
A PRELIMINARY REPORT ON THE TRANSMISSION OF PATHOGENIC GERMS BY THE COMMON HOUSE- FLY
}

By JaColyn manNing, M.D., EaU Claire, Wis,

Graduate of the Illinois Training-School for Nurses and of the Women's Medical College, Chicago

[At this season, when the common house-fly is so much in evidence, extracts from the following reprint from the Journal of the American Medical Associa. tion are timely.-En.]

William Hamilton Gibson, the naturalist and artist, called attention to a troublesome parasite of the house-fly, the microscopic, red, false scorpion. A careful scrutiny of a sheet of adhesive fly-paper in use will show many victims of this inconvenient little handicap, which, once anchored to the fly's leg, remains there, an animated and persistent tag.

A more serious and fatal enemy is the fly fungus, which "silences more house-flies than all the traps and poisons devoted to their extermination." This germ-scourge of flies kills them swiftly, and continues to grow with such rapidity that it perforates the body of its host and spreads around him on the wall or window-glass a white shroud of mould from which spores are wafted, to the peril of next year's flies. That the house-fly acts as host to this fungus is apparent to anyone who will examine with a hand-lens onc of the suspended and inanimate forms seen often during the fall months.

The habit of affording houseroom, whether willingly or unwillingly, to all comers brought Musca domestica prominently before the profession in the last decade, when he fell under suspicion as a carrier of infection in acute intestinal diseases.

The investigation of the Army Medical Commission during the Spanish-American War practically established the fact that the fly is an important factor in the dissemination of typhoid fever.

Victor Vaughan, a member of that commission, stated that flies undoubtedly served as carriers of typhoid infection, giving as reasons for his belief: "They swarmed over fecal matter in the latrines. They 
visited and fed on food prepared for the soldiers in the mess-tents. In some instances, when lime had been recently sprinkled over the contents of latrines, flies, with their feet whitened with lime, were seen walking over the food. Officers whose mess-tents were protected by means of screens suffered less proportionately from typhoid fever than those whose tents were not so protected. Typhoid fever gradually disappeared in the fall of 1898, with the approach of cold weather and the consequent disabling of the fly."

This possibility has been foreseen, for Surgeon-General Dr. Sternberg issued a circular in April, 1898, giving careful directions concerning hygiene, stating: "No doubt typhoid fever, camp diarrhœa, and probably yellow-fever are frequently communicated to soldiers in camps through the agency of flies, which swarm about fecal matter, . . . and directly convey infectious material attached to their feet, or contained in their excreta, to the food which is exposed while being prepared at the common kitchen or while being served in the mess-tent."

An Italian scientist, Celli, demonstrated in 1888 that flies fed on the pure cultures of bacillus typhi abdominalis were able to transmit virulent bacilli into their excrement, and the agency of flies in the transmission of the spirillum of Asiatic cholera has been observed by many scientists.

Dr. L. O. Howard, of the United States Board of Agriculture, recently published the results of experimental work with the house-fly and other diptera extending over a period of five years. He considered that from a scientific and practical viewpoint there was needed a careful investigation of the insect fauna of human excrement, and especially of the flies that breed in human excrement or are attracted to it. Of the serenty-one species of diptera that were found breeding in or frequenting human excrement, the common house-fly (Musca domestica) is reported "abundant;" as also its near relatives, the little house-fly (Homalo-myia canicularis), "moderately abundant," and the stable-fly (Muscina stabulans). To ascertain the practical bearing of this fact numerous collections were made of the diptera frequenting kitchens and pantries. "In all twenty-three thousand and eighty-seven flies were examined which had been caught in rooms in which food supplies were ordinarily exposed, and which may safely be said to have been attracted by the presence of these food supplies." Of this number 98.8 per cent. were the common house-fly, while the little house-fly and the stable-fly composed one-half of the remainder.

Dr. Howard gives an opinion: "That Musca domestica, . . . in such cities and towns, or in such portions of cities, as are well cared for and inhabited by a cleanly and respectable population may not be 
considered an inminent source of danger; it is . . . under other conditions a factor of the greatest importance in the spreal of intestinal diseases."

Of the biting fly (Stonoxys calcitrans) Dr. Howard states: "They resemble the house-fly very closely. The fact that they enter houses hefore storms gives rise to the conmunon expression, "Flies begin to bitc before a rain.' From their biting and blood-sucking habits this insect has been suspected, in common with the truc horse-flies, of earrying the bacillus of anthrax, or malignant pustnle, and there is no reason why it should not transfer any blood-inhabiting micro-organism from donestie animals to man or from onc man to another."

Of another very minute fly (Hippelates flavipes) Dr. Howard says: "The flies are very abundant, especially in the South, where they are found swarming about the eyes of animals and human beings. They are said by Hubbard to be responsible for the transmission of the disease known as 'pinkcye' occasionally prevalent, especially among schoolchildren in Florida. The . . . speeies is perhaps often responsibie for the carriage of putrefactive germs to open wounds, and is indirectly the cause of blood-poisoning."

From the foregoing statements may we not expect to find the everpresent house-fly a direct factor in the transmission of the nnicro-organisms of wound infection?

It has been said that the mosquito carries with her the most perfectly constructed of inoculators, and the housc-fly has, in the specialized strueture of each terminal tarsus, a well-adapted brush for the transmission of adhering gernss. 'The pads, or so-called suction dises, on each foot are rayed with minute hairs, which again terminate in more minute dises; and Chambers states that the last naned "exude a liquid substance which probably serves to make adliesion more perfect." In experimenting it was found that every footprint of an infected fly on sterile culture media was followed by a discrete colony of the germ, thirty to torty distinct colonies sometimes appearing after one journey of the fly across the surface of the culture media.

In the experiments that follow common house-flics were used. They were caught in the kitchen of a dwelling-house, in a physician's office, and in one instance in a lying-in chamber. They were confined separately under reversed tumblers placed on note-paper. A watch-glass containing a sinall portion of the infected material was thrust under the tumbler, and when curiosity had taken the fly across the material he was seized with a sterile forceps wrappcd with cotton, and liberated just at the mouth of a tube of sterile blood-scrum. One stroll across the culture media and the tube was inverted over the flame of an alcohol lamp, which 
incinerated the fly and sterilized the mouth of the tube. The cotton plug and rubber cap of the tube being adjusted, it was placed in an incubator at $37^{\circ} \mathrm{C}$. for twelve hours.

The tubes of sterile culture media were obtained, prepared for use, from a well-known laboratory.

On September 7 the dressings from an infected hand were obtained. The dressings were soaked with blood-serum. There were several areas of greenish and bright-green pus, and an offensive odor diffused on opening them. The surgeon stated the wound had shown an obstinate phlegmonous extension with localized æedcma. A portion of the dressing was placed under an inverted tumbler and two flies confined with it. They immediately lighted on the dressing, crossing it repeatedly before preparations were completed for removing them. In a few moments they moved slowly and appearcd quitc stupid.

Fly A was assisted into a tube of sterile blood-serum with sterile forceps.

Fly B walked into a second tube through a perforation in the notepaper over a tumbler.

In each case, after the fly crossed the surface of the medium, the tube was inverted over an alcohol flame, destroying the fly; the mouth of the tube and cotton plug were flame-sterilized, the plug and rubber cap adjusted, and the tubes placed in an incubator. After eighteen hours thesc tubes were removed from the incubator and presented practically the same appearance; the surface of the medium was freely dotted with small brown colonies; the upper surface of the medium presented a pale-greenish tint. Three days later inspection showed the colonies entirely coalesced; the upper one-half of the media in each tube was a deep bluish-green, the lower onc-half a dull orange; liquefaction of the media had begun at the lower end of the slant. Coverspreads made from these cultures and stained witl Loeffler's alkaline methylene blue showed a pure culture of a small bacillus with rounded ends. . . .

All of the cultures, when opened, cmitted an offensive and purulen odor. From all of these characteristics the germs were identified as the bacilli of green pus. The bacillus of green pus, Gessard's micrococcus pyocyaneus, or the bacillus des grün-blauen Eitcrs, is a widely distributed germ, found in purulent and serous wounds and in the viscera of human cadavers. It is an aërobic, facultative anaërobic, liquefactive, motile, chromogenic and pathogenic germ; in its chromogenic function two pigments are formed, one fluorescent green, the other blue pyocyanin.

The satisfaction felt on coming into possession of a germ so easily identified and tenacious of existence has increascd each week, as other experiments much less satisfactory were undertaken. . . . 
On November 2 a fly was confined with some sputum from a case of bronchitis in its fourth week. A cover-glass spread of the sputum showed diplococci, tetrads, and many staphylococci and streptococci. Two tubes of blood-serum were infected by the fly, and after forty-eighthours' incubation showed manifold and surprising growths. Prominent among the colonies were several of a golden-yellow color and glistening surface. From these colonies cultures were made on the various diagnostic media. A streak culture on Loeffler's blood-serum made a rapid growth, the growth elevated, with wavy edges and a shining golden surface. A streak culture on Koch's blood-serum developed less color and sunk into the medium, channelling a bed for itself, otherwise the medium did not liquefy. On nutrient agar the growth was rapid, of a creamywhite color, with yellow at margin of growth. A gelatin stab culture showed a cloudy liquefaction following stab. Stained cover-glass spreads of the blood-serum cultures showed masses of small cocci, which were identified as the staphylococci pyogenes aureus.

Two tubes inoculated with flies taken from a lying-in chamber early in September showed after incubation one sterile tube and one tube containing many colonies of orange and white sarcinæ; these germs are non-pathogenic, and appeared sooner or later in a majority of the cultures produced by fly-infection.

On one of the tubes-fly-infected from the case of salpingitis-a single colony of bacillus prodigiosus appeared. This germ grows with the production of a brilliant orange-red pigment and is the origin of the miracle of the supposed bleeding wafers. It is non-pathogenic, but its chemical products are toxic and form a part of the Coley sarcoma mixture.

Moulds grew so rapidly on many of the fly-infected tubes that only a few are presentable for inspection, suggesting the probability that flies are often fungus-ridden whether transmitting pathogenic germs or not:

The moulds appeared more rapidly and certainly the last month than the first, and also during the past four weeks the flies have walked less briskly across the surface of media, dragging across; the colonies were not discretely rounded.

During the experimentation forty-four culture tubes have been subjected to fly-infection; of this number forty-one tubes showed colonization at the end of forty-eight hours, three tubes remaining apparently sterile.

The following germs have been transmitted by fly-infection and isolated and pure cultures obtained: Pathogenic germs-bacillus pyocyaneus, staphylococci pyogenes aureus, bacillus typhi abdominalis, bacillus coli communis; non-pathogenic-bacillus prodigiosus, sarcinæ aurantia, sarcinæ alba, moulds, and fungi. 